\title{
Endometrial Cancer in Bicornuate Uterus: Case Report
}

\section{Bikornuat Uterusta Endometrium Kanseri: Olgu Sunumu}

\author{
Osman Türkmen ${ }^{1}$, Oben Esra Tutar ${ }^{1}$, Günsu Kimyon ${ }^{1}$, Mehmet Çelik ${ }^{1}$, Alper Karalök ${ }^{1}$, Heyecan \\ Ökten², Taner Turan¹, Gökhan Tulunay ${ }^{1}$ \\ ${ }^{1}$ Etlik Zübeyde Hanım Kadın Hastalıkları Eğitim Ve Araştırma Hastanesi, Jinekolojik Onkoloji Cerrahisi \\ Kliniği, Ankara \\ ${ }^{2}$ Etlik Zübeyde Hanım Kadın Hastalıkları Eğitim Ve Araştırma Hastanesi, Patoloji Bölümü, Ankara
}

Dergiye Ulaşma Tarihi: 10/01/2016 Dergiye Kabul Tarihi: 01/03/2016 Doi: 10.5505/aot.2017.30074

\section{ÖZET}

Bikornuat uterusta ortaya çıkan endometrial karsinom nadiren rapor edilmiştir. Sunulan olgu 75 yaşında postmenapozal yakınması olan hastada tanımlanmıştır. Daha önce sunulanlardan farkı bikornuat uterusun bir taraftaki boynuzunda endometrial karsinom, diğer taraftaki boynuzunda endometrial polip belirlenmesidir ve bunların her ikisi de postmenapozal kanama nedenidir.

Anahtar Kelimeler: Endometrium kanseri, Bikornuat uterus, Endometrial polip, Postmenapozal kanama

\begin{abstract}
Endometrial carcinomas arising in a bicornuate uterus has been very rarely reported before. Our case report has been identified in 75-year-old patient with postmenopausal bleeding. Unlike previously reported cases, our case showed endometrial carcinoma in one horn and endometrial polyp in the other horn of bicornuate uterus, both of which are among the causes of postmenopausal bleeding.
\end{abstract}

Keywords: Endometrial cancer, Uterus bicornuate, Endometrial polyp, Postmenopausal bleeding

\section{Giriș}

Bikortnuat uterus, müllerian kanalın parsiyel füzyon eksikliğinden kaynaklanan anomalidir. Genellikle birbiriyle ilişkili iki ayrı uterin kavite ve tek bir serviks ile karakterizedir. Füzyon başarısızlığının derecesine göre daha kısmi bir ayrılmayla sonuçlanabileceği gibi ayrılma servikse kadar uzayabilir (1).

Endometrium kanseri en s1k görülen jinekolojik malignitedir. Endometrial biyopsi ile tanı şansının yüksek olduğu bu tümörde anormal vajinal kanama erken dönemde klinik tanı konmasını sağlar. Birincil tedavi histerektomi, bilateral salpingo-ooforektomi ve gereken durumlarda lenfadenektomidir. Hastaların dörtte üçünde sadece cerrahi ile tedavi edilebilen düşük grade düzeyli uterusla sinırlı hastalı mevcuttur. İleri evrelerde adjuvant radyoterapi, kemoterapi veya her ikisi birden gerekebilmektedir (2).

Endometrial polipler yaygındır. Persiste kanaması olan postmenopozal kadınlarda \%38 oranında polip saptanmıştır.
Transvajinal ultrasonografi, sonohisterografi, histerosalpingografi tanı amaçlı kullanılan başlıca görüntüleme yöntemleridir. Tanı ve tedavide histeroskopi altın standarttır (3).

Postmenopozal kanama çoğunlukla iyi huylu patolojilerden kaynaklanır. En sık nedeni atrofidir. Polip başlıca sebepler arasındadır. Olguların büyük çoğunluğunun postmenapozal dönemde olduğu endometrium kanserinde en sik semptom postmenopozal kanamadır ve bu nedenle bu semptomun varlığında tanı amaçlı probe küretaj veya histereskopi ile endometrial örnekleme yapılması gereklidir (4).

Bikornuat uterusda tek başına polip olan kaviteden yapılan örnekleme kanama sebebinin teşhis edildiği yanılgısını doğurup kanser teşhisinin atlanmasına neden olacaktır. $\mathrm{Bu}$ makalede uterus boynuzlarının birinde postmenapozal kanama nedeni olarak benign patoloji olan endometrial polipin diğer boynuzunda ise endometrial kanserin olduğu olgunun sunulması amaçlandı. 
Olgu Sunumu

\section{Olgu}

Obez (vücut kitle indeksi:39 kg/ $\mathrm{m}^{2}$ ), gravida 3, parite 3, ölü doğum 3 ve yaşayan 0 olan 75 yaşındaki hastaya postmenapozal kanama yakınmasıyla dış merkezde endometrial örnekleme yapılmış olup patoloji sonucunun endometrial kanser olarak belirtilmesi üzerine hastanemize yönlendirilmiştir. Jinekolojik muayenesinde patolojik bulgu saptanmamıştır. Transvajinal ultrasonografide 20x39 mm boyutlarında uterus bikornuat görünümde, endometrium kavitelerden birinde $12 \mathrm{~mm}$, diğerinde ise yer yer hipoekoik alanlar içermekle beraber $16 \mathrm{~mm}$ ölçülmüştür. Bilateral overler atrofik olarak tanımlanmıştır. Endometrial biyopsi sonucu malign epitelyal tümör şeklinde rapor edilmiştir. Bunun üzerine yapilan laparotomide uterus didelfis halindeydi, her iki over ve tuba uterina ve diğer intraabdominal organlar normal olarak değerlendirildi. Ekstrafasiyal histerektomi, bilateral salpingo-ooforektomi, pelvik ve paraaortik lenfadenektomi ve omental biyopsiyi içerecek şekilde hastaya evrelendirici cerrahi uyguland1.

Patolojik değerlendirmede; materyalin makroskopisinde uterusta bikornus unikollis anomalisi belirlendi. Sol boynuz boyutu $5 \times 3 \times 1$ $\mathrm{cm}$, sağ boynuz boyutu $4 \times 3 \times 1 \mathrm{~cm}$ ve serviks boyutu $5 \times 4 \mathrm{~cm}$ olarak ölçüldü. Sol taraftaki uterusun kesitinde lümeni tamamen dolduran, polipoid tarzda büyümüş $3 \times 2 \times 0.5 \mathrm{~cm}$ ölçülerinde tümöral lezyon; sağ taraftaki uterusun kesitinde $5 \mathrm{~cm}$ uzunluğunda ve $1 \mathrm{~cm}$ çapında polip yapısı mevcuttu, să endometrium diğer kısımlarda $0.1 \mathrm{~cm}$ ölçüldü (Resim 1).

Histopatolojik incelemede sol taraftaki uterusta grade 1 endometrioid tip adenokarsinom ve sağ taraftaki uterusta endometrial polip tespit edilmiştir (Resim 2). Her iki over ve tuba uterinada patoloji izlenmemiş ve lenf nodları reaktif olarak belirlenmiştir. Nihai patoloji sonucunda hasta 2009 FIGO kriterlerine göre evre 1B olarak tanımlanmıştır.

cerrahi uygulandi.

Patolojik değerlendirmede; materyalin makroskopisinde uterusta bikornus unikollis anomalisi belirlendi. Sol boynuz boyutu $5 \times 3 \times 1$ $\mathrm{cm}$, sağ boynuz boyutu $4 \times 3 \times 1 \mathrm{~cm}$ ve serviks boyutu $5 \times 4 \mathrm{~cm}$ olarak ölçüldü. Sol taraftaki uterusun kesitinde lümeni tamamen dolduran, polipoid tarzda büyümüş $3 \times 2 \times 0.5 \mathrm{~cm}$ ölçülerinde tümöral lezyon; sağ taraftaki uterusun kesitinde $5 \mathrm{~cm}$ uzunluğunda ve $1 \mathrm{~cm}$ çapında polip yapısı mevcuttu, sağ endometrium diğer kısımlarda $0.1 \mathrm{~cm}$ ölçüldü (Resim 1).

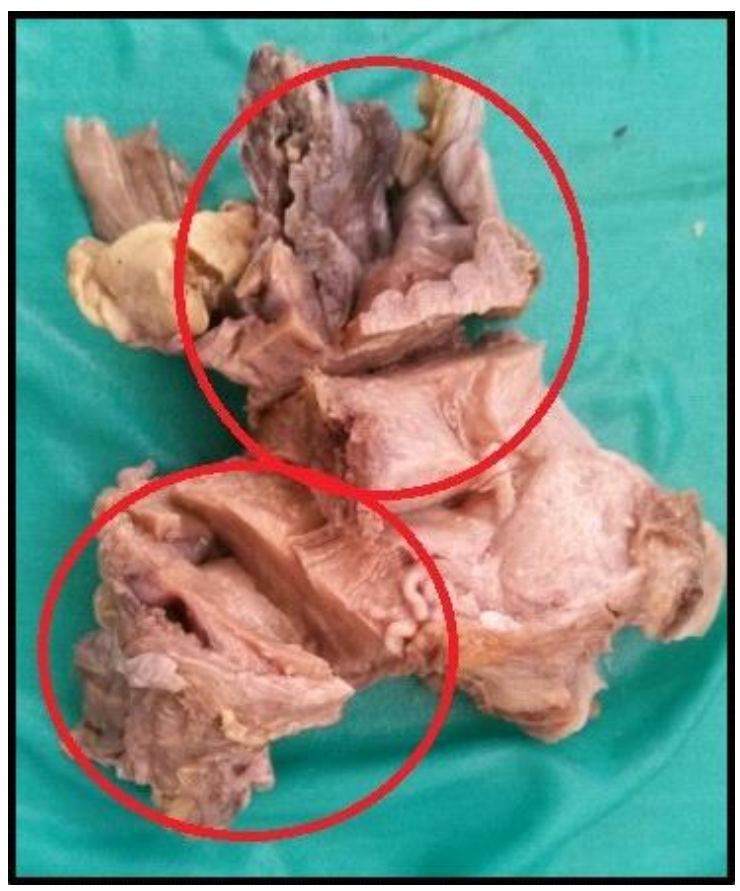

Resim 1. Bicornuat uterus,

ĕgri ok:tümöral lezyon, düz ok: endometrial polip

Histopatolojik incelemede sol taraftaki uterusta grade 1 endometrioid tip adenokarsinom ve sağ taraftaki uterusta endometrial polip tespit edilmiştir (Resim 2). Her iki over ve tuba uterinada patoloji izlenmemiş ve lenf nodları reaktif olarak belirlenmiştir. Nihai patoloji sonucunda hasta 2009 FIGO kriterlerine göre evre 1B olarak tanımlanmıştır.

\section{Tartışma}

Uterin malformasyonlar ile endometrial kanser risk artışı arasında bildirilmiş bir ilişki yoktur (5). Bicornuat uterusta gelișen endometrial kanser vakası oldukça nadir rapor edilmiștir. Çoğu olguda tek boynuzda endometrium kanseri görülmekte iken, daha nadir olarak her iki uterus boynuzunda endometrium kanserinin geliştiği olgular da sunulmuştur $(6,7)$.

Sunulan olguda soldaki uterusta endometrium kanseri mevcutken sağdakinde endometrial polip saptand. Endometrium kanseri ve endometrial polip kadınlarda 


\section{Olgu Sunumu}

anormal vajinal kanamaya sebep olabilmektedir. Anormal vajinal kanamalarda hedef kanseri dişlamak ve altta yatan nedeni saptamaktır. Kanseri ekarte etmek için endometrial biyopsi önemlidir. Bikornuat uterusda nadiren her iki boynuzda kanser meydana gelmektedir. $\mathrm{Bu}$ nedenle tek boynuzdan örnekleme kanser tansının atlanmasina sebep olabilir.

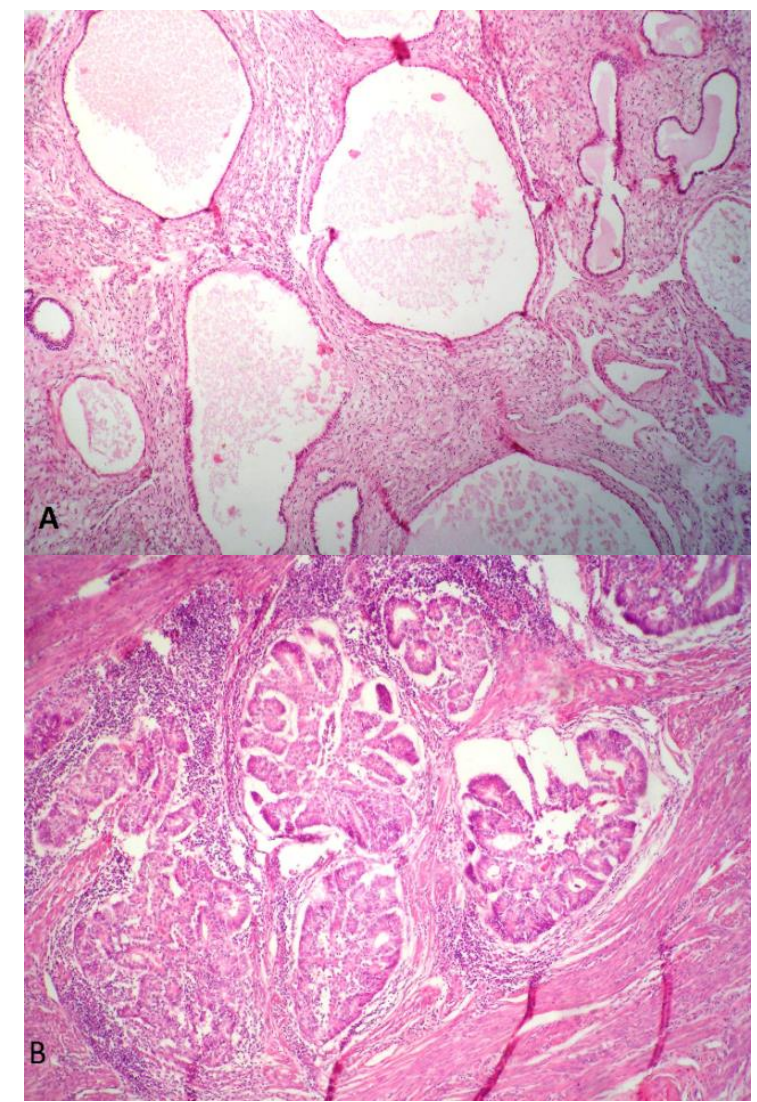

Resim 2. Olgunun mikroskopik histopatolojik bulguları (A) Endometrial polip; (B)Endometrioid tip adenokarsinom, grade 1
Bikornuat uterus anomalisi nadir görülmesine rağmen bu anomaliye sahip olan kadınların belirlenmesi tanı atlanmaması açısından değerlidir. Her iki kavitenin dikkatli şekilde taranmas1 gerekmekte olup tek kavitenin taranması tanı eksikliğine yol açabilir.

\section{Çıkar çatışması: Yok}

\section{Kaynaklar}

1. Bradshaw K D. Chapter 18 Anatomic disorders, sayfa: 850, In: Schorge J O, Williams J W (eds). Williams Gynecology. McGraw-Hill Medical, New York, 2008

2. Schorge J O, Miller D S. Chapter 33 Endometrial Cancer, sayfa: 1370, In: Schorge J O, Williams J W (eds). Williams Gynecology. McGraw-Hill Medical, New York, 2008

3. Yaşar L, Arıcı B. Endometriyal poliplerde sayı, çap ve lokalizasyonun; laboratuvar, klinik ve histopatolojik bulgularla ilişkisi, T. C. Sağlık Bakanlığı Bakırköy Dr Sadi Konuk Eğitim ve Araştırma Hastanesi ve Doğum Kliniği, 2009

4. Munot S, Lane G. Modern management of postmenopausal bleeding. Trends in Urology, Gynaecology \& Sexual Health 2008; 13(5):20-24

5. Renaud M C, Le T. Epidemiology and investigations for suspected endometrial cancer. Joint Sogc-GocScc Clinical Practice Guideline 2013; 35(4):380-381

6. Shirley S, Devi V, Krishnamurthy R, Nabhi M, Majhi U, Selvaluxmy G. Endometrial adenocarcinoma involving both horns of a bicornuate uterus. Journal of Cancer Research and Therapeutics 2010; 6(3):304306

7. Munkhdelger J, Mia-Jan K, Soo Cha D, Eom M. Endometrial carcinoma arising in a bicornuate uterus. Obstet Gynecol Sci. 2014; 57(5): 401-404 